\title{
Persepsi Siswa Tentang Pelayanan Tenaga Administrasi Sekolah di SMKN 1 Enam Lingkung
}

Pungki Cindy Ashari ${ }^{1}$, Hadiyanto $^{2}$, Nellitawati ${ }^{3}$, Ermita $^{4}$

1,2,3,4Administrasi Pendidikan, Universitas Negeri Padang

Author ${ }^{1}$, e-mail: cindyazhari07@gmail.com

*Author ${ }^{2}$, e-mail: hadiyanto@fip.unp.ac.id

*Author ${ }^{3}$, e-mail: nellitawati@fip.unp.ac.id

*Author ${ }^{4}$, e-mail: ermita@fip.unp.ac.id

\begin{abstract}
This study is based on obtaining an overview of students perceptions of the service of school administrative personnel. The study uses quantitative research methods. As for the population of this study were students of class X and class XI at SMKN 1 Enam Lingkung. This study shows students perceptions about the service of school adminitrative personnel in SMKN 1 Enam Lingkung: a) the friendlinnes aspect with an average score of $4,16, b$ ) the comfort aspect with an average score of $4,13, \mathrm{c}$ ) the responsibility aspect with an average score of $4,11, \mathrm{~d}$ ) the responsiveness aspect with an average score of 4,15 , e) the aspect of ease of with service had an average score of 4,20 . Be concluded that students perceptions of service of school administrative personnel at SMKN 1 Enam Lingkung with an average score of 4,15 . Suggestions that can be given are efforts to maintain and improve the service for school administrative personnel to make it better.
\end{abstract}

\begin{abstract}
Abstrak
Penelitian ini dilandasi untuk mendapatkan gambaran tentang persepsi siswa mengenai pelayanan tenaga administrasi sekolah. Penelitian ini menggunakan metode penelitian kuantitatif. Adapun populasi dari penelitian ini adalah siswa kelas X dan kelas XI di SMKN 1 Enam Lingkung. Dari penelitian ini menunjukkan persepsi siswa tentang pelayanan tenaga administrasi sekolah di SMKN 1 Enam Lingkung: a) aspek keramahan dengan skor rata-rata 4,16, b) aspek kenyamanan dengan skor rata-rata 4,13, c) aspek tanggung jawab dengan skor rata-rata 4,11, d) aspek ketanggapan dengan skor rata-rata 4,15, e) aspek kemudahan dalam pelayanan dengan skor rata-rata 4,20. Kesimpulannya bahwa persepsi siswa mengenai pelayanan tenaga adminsitrasi sekolah di SMKN 1 Enam Lingkung dengan skor rata-rata 4,15. Saran yang dapat diberikan adalah upaya untuk mempertahankan dan meningkatkan pelayanan tenaga administrasi sekolah agar menjadi lebih baik.
\end{abstract}

Kata Kunci:persepsi, pelayanan tenaga administrasi sekolah

How to Cite: Author 1, and Author 2. Year. Title Manuscript. Journal Educational Administration and Leadership, Vol (N): pp. XX-XX, DOI:10.24036/XXXXXXXXXX-X-XX use, distribution, and reproduction in any medium, provided the original work is properly cited. $\odot 2020$ by author.

\section{Pendahuluan}

Pelayanan yang baik mencerminkan bagaimana cara tenaga dalam memberikan pelayanan terbaik kepada siswa, sehingga dari adanya kepuasaan tersebut dapat menunjukkan tanda bahwasannya layanan yang dilakukan oleh tenaga administrasi sekolah dalam pelayanan tersebut dengan baik. 
Dalam pembahasan ini terdapat beberapa masalah yang timbul pada pelayanan ialah masih ada beberapa tenaga administrasi yang masih kurang dalam pelayanan kepada siswa, dari itu siswa sering merasa kurang puas. Adapun beberapa kekurangan dalam pelayanan tenaga administrasi sekolah ialah kurang ramah dan adil dalam pelayanan, dalam cara berbicara tenaga administrasi kurang sopan dan kurang jelas dalam penyampaian informasi. Hal inilah yang mempengaruhi pencapaian tujuan dalam pelayanan, karena memberikan rasa tidak nyaman dalam penggunaan pelayanan tersebut.

Pelayanan tenaga administrasi sekolah terbilang masih belum sesuai dengan yang diharapkan. Sebagai berikut ada beberapa fenomena yang dapat dilihat:

a. Beberapa dari tenaga administrasi lebih mengutamakan dan mendahulukan pelayanan kepada peserta didik yang dikenal dan dekat dengan tenaga administrasi yang kurang objektif dalam memberikan pelayanan. Sehingga peserta didik merasa dibeda-bedakan serta tidak mendapat perlakuan dan pelayanan yang adil.

b. Sedikitnya tenaga administrasi dalam pelayanan disekolah. Sehingga pekerjaan tenaga administrasi sering tidak selesai sesuai dengan waktunya

c. Dalam berbicara dan bersikap tenaga administrasi dirasa kurang sopan dan ramah saat melayani peserta didik. Sehingga siswa cenderung merasa tidak dihargai.

d. Cara berbicara tenaga administrasi terlihat bingung dan ragu dalam menjawab pertanyaan yang ditanyakan peserta didik dan pemberian informasi yang kurang tepat dan akurat dalam pelayanan. Sehingga peserta didik merasa bingung dan tidak jelas dengan informasi yang dijawabnya .

Tenaga administrasi sekolah sering mengulur waktu pekerjaan dalam pelayanan dan bahkan dalam menyelesaikan masalah pekerjaan yang diajukan peserta didik. Sehingga tenaga administasi sekolah terkesan mempersulit urusan peserta didik tanpa alasan yang jelas.

\section{Metode Penelitian}

Jenis penelitian ini adalah deskriptif. Adapun populasi pada penelitian ini adalah seluruh peserta didik pada kelas X dan XI di SMKN 1 Enam Lingkung yang berjumlah 528 peserta didik menggunakan teknik Proportional Stratifed Random Sampling. Pengumpulan data penelitian ini menggunakan angket dan kuesioner yang diisi oleh kelas X dan kelas XI di SMKN 1 E nam Lingkung. Prosedur menganalisis data yaitu verifikasi data,pemberian skor jawaban responden, menghitung skor rata-rata dan menentukan tingkat persepsi siswa.

\section{Hasil dan Pembahasan \\ Hasil}

a. Tentang Keramahan Pelayanan Tenaga Administasi Sekolah

Dalam aspek ini persepsi siswa dilihat dari sub indikator ialah: a) keramahan dan b) kepedulian. Dari keseluruhan hasil di dapat dari aspek keramahan di SMKN 1 Enam Lingkung yaitu dengan skor rata-rata 4,16 .

Skor terbaik mengenai persepsi siswa tentang pelayanan tenaga administrasi sekolah dari aspek keramahan yaitu bersikap ramah ketika meminta informasi mengenai beasiswa kurang mampu yang diberikan dengan skor 4,35 (Baik). Sedangkan yang mendapatkan skor terendah yaitu mendahulukan kebutuhan siswa yang datang dahulu dariada siswa yang dikenalnya dengan skor 3,98 (Baik).

b. Tentang Kenyamanan Pelayanan Tenaga Administrasi Sekolah

Dalam aspek ini persepsi siswa dilihat dari sub indikator ialah: a) kebersihan lingkungan dan b) peralatan yang mendukung dalam pelaksanan kerja. Dari keseluruhan hasil di dapat dari aspek kenyamanan di SMKN1 Enam Lingkung yaitu dengan skor 4,13.

Skor terbaik mengenai persepsi siswa tentang pelayanan tenaga administrasi sekolah dari aspek kenyamanan yaitu bagian kebersihan menjaga dan melaksanakan kebersihan ruang dan semua bangunan disekolah yang ada dengan skor rata-rata 4,43 (Baik). Sedangkan yang mendapatkan skor terendah yaitu tidak menggunakan fasilitas yang ada disekolah untuk kepentingan pribadi dengan skor rata-rata 3,40 (Cukup).

c. Tentang Tanggung Jawab Pelayanan Tenaga Administrasi Sekolah

Dalam aspek ini persepsi siswa dapat dilihat dari sub indikator ialah: a) memeiliki tanggung jawab dan b) dapat bekerjasama dengan tim. Dari keseluruhan hasil di dapat dari aspek tanggung jawab di SMKN 1 Enam Lingkung yaitu dengan skor 4,11.

Skor terbaik mengenai persepsi siswa tentang pelayanan sekolah dari aspek tanggung jawab yaitu menunjukkan sikap tanggung jawab terhadap siswa dengan memenuhi pelayanan yang dibutuhkan siswa dengan skor rata-rata 4,50(Baik). Sedangkan yang mendapatkan skor terendah yaitu tidak memberikan tugasnya ke yang lain ketika melayani siswa dengan skor rata-rata 3,50 (Cukup).

d. Tentang Ketanggapan Pelayanan Tenaga Administrasi Sekolah

Dalam aspek ini persepsi siswa dilihat dari sub indikator yaitu: a) punya fleksibilitas, b) punya kesadaran, c) bisa berkomunikasi secara efektif, dan d) bisa membuat hubungan kerja yang baik. Dari keseluruhan hasil di dapat dari aspek ketanggapan di SMKN 1 Enam Lingkung yaitu dengan skor 4,15. 
Skor terbaik mengenai persepsi siswa tentang pelayanan tenaga administrasi sekolah dari aspek ketanggapan yaitu ketika memberikan pelayanan terhadap siswa cepat tanggap dengan keluhan siswa yang diberikan dengan skor rata-rata 4,50 (Baik). Sedangkan yang mendapatkan skor terendah yaitu mudah bersosialisasi dengan siswa saat melayani dengan skor rata-rata 3,64 (Baik.)

e. Tentang Kemudahan dalam Mendapatkan Pelayanan Tenaga Administrasi Sekolah

Dalam aspek ini persepsi siswa dilihat dari sub indikator ialah: a) mampu memberikan pelayanan prima dan b) kesesuaian hasil kerja yang bermutu. Dari keseluruhan hasil di dapat dari aspek kemudahan dalam mendapatkan pelayanan di SMKN 1 Enam Lingkung yaitu dengan skor 4,20.

Skor terbaik mengenai persepsi siswa tentang pelayanan tenaga administrasi sekolah dari aspek kemudahan dalam mendapatkan pelayanan yaitu tenaga adminsitrasi sekolah memberikan pelayanan kepada siswa dengan nyaman dan cepat yang diberikan dengan skor rata-rata 4,60 (Baik). Sedangkan yang mendapatkan skor terendah yaitu tenaga administrasi sekolah tidak membeda-bedakan siswa saat melayani yang diberikan dengan skor rata-rata 3,89 (Baik).

\section{f. Rekapitulasi Skor Rata-rata Tentang Pelayanan Tenaga Administrasi Sekolah}

Skor terbaik persepsi siswa tentang pelayanan tenaga administrasi sekolah yaitu pada aspek kemudahan dalam mendapatkan pelayanan yang memperoleh rata-rata skor 4,20. Sedangkan skor terendah yaitu pada aspek tanggung jawab dengan skor rata-rata 4,11. Jadi secara keseluruhan persepsi siswa tentang pelayanan sekolah berada pada kategori baik.

\section{Pembahasan}

\section{a. Tentang Pelayanan Tenaga Administrasi0Sekolah dari Aspek Keramahan}

Salah satu indikator dari persepsi siswa tentang pelayanan tenaga administrasi sekolah adalah keramahan. Hasil penelitian menunjukkan keramahan mendapat skor rata-rata 4,16, sehingga perlu usaha untuk mempertahankan dan meningkatkan keramahan tenaga administrasi sekolah dalam melayani siswa untuk jauh lebih baik. Hasil penelitian menunjukkan skor tertinggi ada pada item tenaga administrasi sekolah ramah ketika siswa meminta informasi tentang beasiswa kurang mampu yang memperoleh skor rata-rata 4,35. Dan skor rata-rata terendah yaitu tenaga administrasi sekolah mendahulukan kebutuhan siswa yang datang terlebih dahulu daripada siswa yang dikenalnya dengan memperoleh skor 3,98.

Penyebab rendahanya rata-rata skor pada pernyataan tenaga administrasi mendahulukan siswa yang datang terlebih dahulu daripada siswa yang dikenalnya dikarenakan item pernyataan ini merupakan item pernyataan negatif karena bersangkutan dengan keadilan siapa yang akan dilayani terlebih dahulu maka sudah seharusnya memiliki skor terendah. Solusi yang diharapkan kedepannya perlunya peningkatan kembali oleh tenaga administrasi sekolah dalam hal pelayanan dengan keramahan dan sesuai dengan siapa yang memerlukan terlebih dahulu dengan baik.

\section{b. Tentang Pelayanan Tenaga Administrasi Sekolah dari Aspek Kenyamanan}

Salah satu indikator dari persepsi siswa tentang pelayanan tenaga administrasi sekolah adalah kenyamanan. Hasil penelitian menunjukkan aspek kenyamanan memperoleh poin rata-rata 4,13 yang pada kategori baik, sehingga perlu upaya untuk lebih meningkatkan kenyamanan dalam pelayanan dalam melayani siswa sehingga akan terbentuk suasana yang lebik baik. Hasil penelitian menunjukkan skor terbaik pada item pernyataan yaitu bagian kebersihan menjaga dan melaksanakan kebersihan ruang seluruh bangunan yang ada disekolah dengan skor rata-rata yang diperoleh yaitu 4,4. Sedangkan skor terendah dalam kenyamanan adalah menggunkan fasilitas yang mendukung dalam memberikan pelayanan kepada siswa dengan memperoleh skor 3,40.

Penyebab rendahnya rata-rata skor pada pernyataan tenaga administrasi menggunakan fasilitas yang mendukung dalam memberikan pelayanan kepada siswa dikarenakan item pernyataan ini merupakan item pernyataan yang mungkin bertolak belakang dengan keadaan sekolah yang mana mungkin fasilitas yang belum cukup mendukung. Solusi yang diharapkan agar adanya upaya untuk meningkatkan fasilitas pendukung dalam melayani siswa agar sesuai dengan yang diharapkan tenaga administrasi sekolah maupun oleh siswa.

\section{c. Tentang Pelayanan Tenaga Administrasi Sekolah dari Aspek Tanggung Jawab}

Salah satu indikator dari persepsi siswa tentang pelayanan tenaga administrasi sekolah adalah tanggung jawab. Hasil penelitian menunjukkan aspek tanggung jawab memperoleh poin rata-rata 4,11 yang sudah berada pada kategori baik, sehingga hanya perlu untuk lebih meningkatkan tanggung jawab terhadap pelayanan tenaga administrasi sekolah pada sikap tanggung jawab terhadap siswa dengan memenuhi pelayanan yang dibutuhkan siswa pada poin rata-rata 4,50. Sedangkan skor rata-rata terendah adalah tidak melimpahkan tugasnya kepada orang lain ketika melayani siswa pada rata-rata 3,50.

Penyebab rendahnya rata-rata skor pada pernyataan tidak melimpahkan tugasnya kepada orang lain ketika melayani siswa dikarenakan item pernyataan ini merupakan item pernyataan yang mungkin sering terjadi saat pelayanan berlangsung. Solusi yang diharapkan tenaga administrasi untuk meningkatkan rasa tanggung jawab terhadap pekerjaan pada bidangnya masing-masing dalam pelayanan. 


\section{d. Tentang Pelayanan Tenaga Administrasi Sekolah dari Aspek Ketanggapan}

Salah satu indikator persepsi siswa tentang pelayanan tenaga administrasi sekolah adalah ketanggapan yang memperoleh skor rata-rata 4,15 yang berada pada kategori baik, sehingga cukup perlu meningkatkan kembali ketanggapan dalam proses pelayanan kedepannya. Hasil penelitian menunjukkan skor tertinggi ada item tenaga administrasi sekolah ketika memberikan pelayanan terhadap siswa cepat tanggap dengan keluhan siswa dengan memperoleh skor rata-rata 4,50. Sedangkan skor terendah adalah tenaga administrasi sekolah mudah bersosialisasi dengan siswa saat melayani dengan memperoleh skor rata-rata 3,64 .

Penyebab rendahnya rata-rata skor pada pernyataan tenaga administrasi sekolah mudah bersosialisasi dengan siswa saat melayani dikarenakan mungkin tenaga administrasi sekolah ada beberapa yang tidak jauh umurnya dengan siswa saat ini sehingga siswa merasa tidak jauh beda dengan tenaga administrasi sekolah. Solusi yang diharapkan kedepannya tenaga administrasi sekolah menempatkan diri sebagaimana seorang tenaga administrasi sekolah harus bisa bersikap professional dan tegas dalam melayani keperluan siswa di sekolah dengan baik.

e. Tentang Pelayanan Tenaga Administrasi Sekolah dari Aspek Kemudahan dalam Mendapatkan Pelayanan

Salah satu indikator dari persepsi siswa tentang pelayanan tenaga administrasi sekolah adalah kemudahan dalam mendapatkan pelayanan. Menurut Wen Et Al dalam jurnal penelitian (Wulan,2009) adalah situasi dimana clien merasa puas dalam berinteraksi dan menerima segala informasi yang telah diberikan. Hasil penelitian menunjukkan aspek kemudahan dalam mendapatkan pelayanan memperoleh skor rata-rata 4,20 yang termasuk dalam kategori baik, sehingga perlu usaha untuk lebih meningkatkan kemudahan dalam mendapatkan pelayanan terhadap pelayanan tenaga adminisrasi sekolah dalam melayani siswa sehingga menjadi lebih efektif dan efisien. Hasil penelitian menunjukkan skor terbaik ada pada item tenaga administrasi sekolah memberikan pelayanan kepada siswa dengan nyaman dan cepat dengan memperoleh skor rata-rata 4,60. Sedangkan skor terendah adalah tenaga administrasi sekolah tidak membeda-bedakan siswa dalam pelayanan dengan memperoleh skor rata-rata 3,89.

Penyebab rendahnya rata-rata skor pada pernyataan tenaga administrasi sekolah tidak membedabedakan siswa dalam pelayanan dikarenakan mungkin ada beberapa siswa yang merasa dibeda-bedakan saat memerlukan bantuan tenaga administrasi sekolah. Solusi yang diharapkan kedepannya tenaga adminsitrasi sekolah dapat meningkatkan kinerja lebih baik dengan tidak membeda-bedakan atau memilih siapa yang akan dilayani terlebih dahulu untuk kepuasan bersama dalam pengguna layanan di sekolah.

\section{f. Rekapitulasi Data Tentang Pelayanan Tenaga Administrasi Sekolah}

Hasil temuan terendah yang didapat dari pengisian angket secara langsung yang diisi oleh responden berdasarkan indikator yaitu:

Tabel 1. Rekapitulasi Sampel

\begin{tabular}{|c|c|c|c|}
\hline No. & Indikator & Skala Nilai & Kategori \\
\hline 1. & Keramahan & 3,98 & Baik \\
\hline 2. & Kenyamanan & 3,40 & Cukup \\
\hline 3. & Tanggung Jawab & 3,50 & Cukup \\
\hline 4. & Ketanggapan & 3,64 & Baik \\
\hline 5. & $\begin{array}{c}\text { Kemudahan dalam } \\
\text { Mendapatkan Pelayanan }\end{array}$ & 3,89 & Baik \\
\hline \multicolumn{2}{|l}{ Jumlah } & 3,68 & Baik \\
\hline
\end{tabular}

\section{Kesimpulan}

Berdasarkan hasil dari penelitian dan pembahasan mengenai pelayanan tenaga administrasi sekolah dapat disimpul sebagai berikut: a) pelayanan tenaga administrasi sekolah dari aspek keramahan berada pada kategori baik dengan skor rata-rata 4,16, b) pelayanan tenaga administrasi sekolah dari aspek kenyamanan berada pada kategori baik dengan skor 4,13 dan kategori cukup dengan skor rata-rata 3,40, c) pelayanan tenaga administrasi sekolah dari aspek tanggung jawab berada pada skor rata-rata 4,11 dan kategori cukup dengan skor rata-rata 3,50, d) pelayanan tenaga administrasi sekolah dari aspek ketangggapan berada pada kategori baik dengan skor 4,15, e) pelayanan tenaga administrasi sekolah berada kategori baik dengan skor rata-rata 4,20 .

\section{Daftar Rujukan}

Ary H. Gunawan. (2002). Administrasi Sekolah. Rineka Cipta.

Dahlan, dkk. (1995). Kamus Besar Bahasa Indonesia. Balai Pustaka.

Devi Yunisa, H. (2019). Persepsi Guru Madrasah Negeri Terhadap Pelayanan Terpadu Satu Pintu (PTSP) Di 
Pungki Cindy Ashari ${ }^{1}$, Hadiyanto $^{2}$, Nellitawati ${ }^{3}$, Ermita $^{4}$ Persepsi Siswa Tentang Pelayanan Tenaga Administrasi Sekolah di SMKN 1 Enam Lingkung

Kantor Kementerian Agama Kota Bukittinggi. Jurnal Bahana Manajemen Pendidikan. Hadiyanto. (2016). Teori dan Pengembangan Iklim Kelas dan Iklim Sekolah. Kencana.

Sugiyono. (2012). Metode Penelitian Administrasi. Alfabeta. 